\title{
Living Cationic Polymerization of Cyclic Unsaturated Ethers
}

\author{
Yukio Ogawa, Mitsuo Sawamoto, and Toshinobu Higashimura \\ Department of Polymer Chemistry, Faculty of Engineering, \\ Kyoto University, Kyoto 606, Japan
}

(Received February 27, 1984)

\begin{abstract}
The living cationic polymerization of 5-methyl-2,3-dihydrofuran (MeDHF; 4) has been achieved with acetyl perchlorate $\left(\mathrm{AcClO}_{4}\right)$ as an initiator in a nonpolar solvent (toluene) at $-78^{\circ} \mathrm{C}$ to give nearly monodisperse polymers $\left(M_{w} / M_{n} \sim 1.1\right)$. Under these conditions, the numberaverage molecular weight $\left(M_{n}\right)$ of the polymer increased in proportion to conversion, and it further increased on addition of a new monomer-feed to a completely polymerized solution. The $M_{n}$ values were in good agreement with the calculated values for living polymers. Similar increases in $M_{n}$ with conversion were observed in the MeDHF polymerizations by $\mathrm{AcClO}_{4}$ in $\mathrm{CH}_{2} \mathrm{Cl}_{2}$ or by iodine in both toluene and $\mathrm{CH}_{2} \mathrm{Cl}_{2}$, but the product polymers showed broader molecular weight distributions. These polymerizations thus involve long-lived (though not perfectly living) propagating species. 2,3-Dihydrofuran (3) also gave long-lived polymers, when polymerized with iodine in toluene and $\mathrm{CH}_{2} \mathrm{Cl}_{2}$ at $-40^{\circ} \mathrm{C}$. Therefore, these unsaturated cyclic ethers give living/long-lived species over a range of reaction conditions wider than that for the corresponding linear monomers (substituted vinyl ethers).
\end{abstract}

KEY WORDS 2,3-Dihydrofuran / 5-Methyl-2,3-dihydrofuran / Iodine /

Acetyl Perchlorate / Cationic Polymerization / Living Polymer / Monodisperse Polymer /

Recent studies in our laboratory have shown that vinyl ethers $\left(\mathrm{CH}_{2}=\mathrm{CH}-\mathrm{OR} ; 1\right)^{1-3}$ and propenyl ethers $\left(\mathrm{CH}_{3}-\mathrm{CH}=\mathrm{CH}-\mathrm{OR} ; 2\right),{ }^{4}$ having an electron-donating alkoxyl group, give living/long-lived polymers, when polymerized with iodine or a mixture of hydrogen iodide and iodine as an initiator in nonpolar solvents at low temperatures. The olefinic monomers that have been found so far to undergo living cationic polymerization, ${ }^{5}$ in general, are all linear (acyclic) and have an electron-donating substituent; e.g. 1, 2, p-methoxystyrene, ${ }^{6,7}$ and $N$-vinylcarbazole. ${ }^{8,9}$

Another class of unsaturated ethers includes cyclic derivatives such as 2,3-dihydrofuran (DHF; 3) and 5-methyl-2,3-dihydrofuran (MeDHF; 4), which are regarded, respectively, as a $\beta$-substituted vinyl ether $\left(\mathrm{R}^{\prime}-\mathrm{CH}=\mathrm{CH}-\right.$ $\mathrm{OR})$ and an $\alpha, \beta$-disubstituted vinyl ether [ $\mathrm{R}^{\prime}-$ $\left.\mathrm{CH}=\mathrm{CR}^{\prime \prime}(\mathrm{OR})\right]$. Although $\mathrm{DHF}^{10-12}$ and
MeDHF ${ }^{10,13-15}$ are known to give high polymers cationically, it has not been clarified whether these five-membered cyclic ethers can form living polymers, similarly to their linear counterparts 1 and 2.

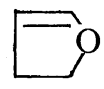

3

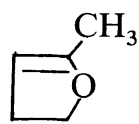

4
In this study we examined the possibility of living cationic polymerizations of DHF and MeDHF with a variety of initiators. The effects of the monomer structure (cyclic $v s$. linear) and the $\alpha$-methyl group in MeDHF on living polymerization are discussed, in comparison with the results for the corresponding linear (propenyl) ethers $2 .^{4}$ 


\section{EXPERIMENTAL}

\section{Materials}

DHF (Tokyo Kasei) was distilled over $\mathrm{CaH}_{2}$ before use. MeDHF was synthesized by the base-catalyzed dehydrobromination of commercial tetrahydrofurfuryl bromide (Wako Chemicals), ${ }^{16}$ and purified by distillation over $\mathrm{CaH}_{2}$ before use. The gas chromatographic purities of both monomers were higher than $99 \%$. Commercial iodine (Wako Chemicals, purity $\geq 99.8 \%$ ) and trifluoromethanesulfonic acid $\left(\mathrm{CF}_{3} \mathrm{SO}_{3} \mathrm{H}\right)$ (Sumitomo 3M, purity $\geq 98 \%$ ) were used without further purification. Boron trifluoride etherate $\left(\mathrm{BF}_{3} \mathrm{OEt}_{2}\right)$, stannic chloride $\left(\mathrm{SnCl}_{4}\right)$, and methanesulfonic acid $\left(\mathrm{CH}_{3} \mathrm{SO}_{3} \mathrm{H}\right)$ were purified by distillation. Acetyl perchlorate $\left(\mathrm{AcClO}_{4}\right)$ was synthesized as described elsewhere. ${ }^{17}$ Toluene and methylene chloride were purified by the usual methods and distilled at least twice over $\mathrm{CaH}_{2}$ just before use. $n$-Octane as the internal standard for gas chromatography was purified in the same way.

\section{Procedures}

Polymerization was carried out under dry nitrogen at -40 and $-78^{\circ} \mathrm{C}$ in a test tube equipped with a three-way stopcock. In this procedure the polymerization system contained $0.2-0.3 \mathrm{mM}$ water as an impurity. The reaction was initiated by adding an initiator solution to a monomer solution and terminated after a certain period with pre-chilled ammoniacal methanol. Monomer conversion was determined by gas chromatography with $n$-octane as the internal standard and also by gravimetry of the product; the values by the two methods were in good agreement.

The quenched reaction mixture was washed with a dilute alkali solution, evaporated to dryness under reduced pressure, and vacuumdried to give white powdery polymers. The polymerization solutions with iodine were washed with $\mathrm{ca}$. $10 \%$ aqueous sodium thiosulfate solution prior to the above-described work-up.

The molecular weight distribution (MWD) of the polymers was measured by gel permeation chromatography (GPC) in chloroform on a Jasco TRIROTAR high-performance liquid chromatograph equipped with three polystyrene gel columns (Shodex A802, A803, and A804). The number-average molecular weight $\left(M_{n}\right)$ and the polydispersity ratio $\left(M_{w} / M_{n}\right)$ were calculated from GPC curves on the basis of polystyrene calibration. The $M_{n}$ of some polymer samples was also measured by vapor pressure osmometry (VPO) in benzene at $30^{\circ} \mathrm{C}$ on a Hitachi- 117 molecular weight apparatus. ${ }^{1} \mathrm{H}$ and ${ }^{13} \mathrm{C}$ NMR spectra were obtained in $\mathrm{CDCl}_{3}$ at room temperature using a JEOL FX-90Q spectrometer.

\section{RESULTS AND DISCUSSION}

\section{Polymerization of 2,3-Dihydrofuran}

Polymerization with Iodine. DHF was polymerized in a polar $\left(\mathrm{CH}_{2} \mathrm{Cl}_{2}\right)$ and nonpolar (toluene) solvent at $-40^{\circ} \mathrm{C}$ with iodine as an initiator. This halogen is known to generate long-lived polymers from vinyl ethers at low temperatures. ${ }^{5}$ In both solvents, polymerization proceeded without an induction period and was completed within $2 \mathrm{~h}\left([\mathrm{DHF}]_{0}=\right.$ $\left.0.20 \mathrm{M} ;\left[\mathrm{I}_{2}\right]_{0}=4.5-9.0 \mathrm{mM}\right)$. The addition of a fresh DHF feed to the completely polymerized reaction mixture in toluene led to further polymerization at a similar rate, indicating the absence of termination.

Figures 1 and 2 show, respectively, the MWD and $M_{n}$ (by GPC) of the resulting polymers as a function of DHF conversion. The MWD was rather broad $\left(M_{w} / M_{n}=1.6\right.$ 2.0) but shifted toward a higher molecular weight region as the reaction proceeded. The $M_{n}$ increased progressively with conversion, and it further increased on the addition of a new monomer-feed (Figure 2). These results indicate that in both polar and nonpolar solvents, long-lived propagating species are formed from DHF by iodine. 

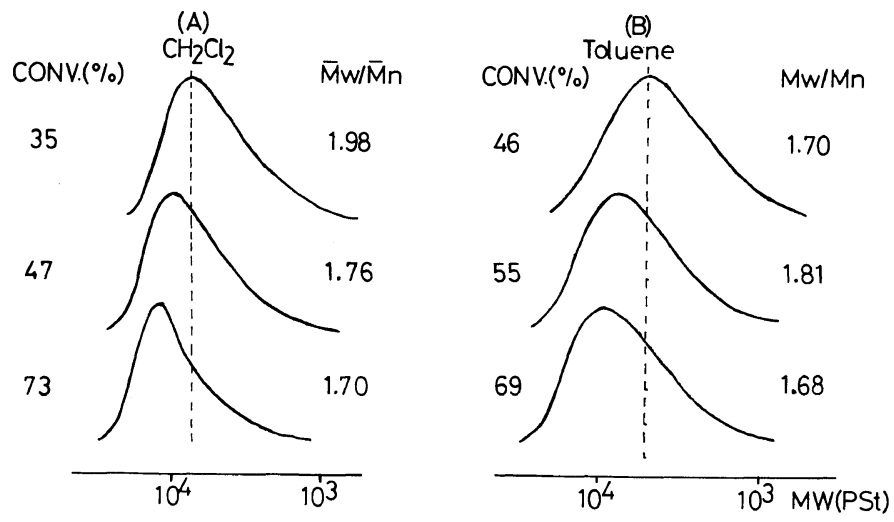

Figure 1. MWD of poly(DHF) obtained with iodine at $-40^{\circ} \mathrm{C}$. $[\mathrm{M}]_{0}$ and $[\mathrm{C}]_{0}:(\mathrm{A}) 0.50 \mathrm{M}, 2.0 \mathrm{mM}$; (B) $0.20 \mathrm{M}, 9.0 \mathrm{mM}$. Solvents as indicated.

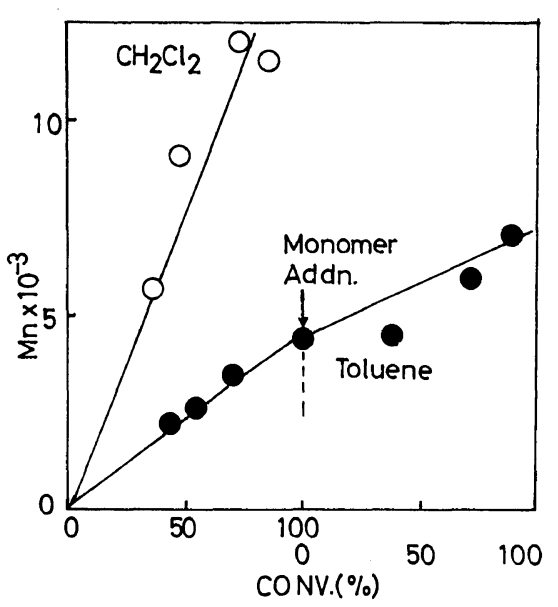

Figure 2. $M_{n}$-conversion plots for poly(DHF) obtained with iodine at $-40^{\circ} \mathrm{C}:(\mathrm{O})[\mathrm{M}]_{0}=0.50 \mathrm{M},\left[\mathrm{I}_{2}\right]_{0}=$ $2.0 \mathrm{mM} ; \quad$ (O) $[\mathrm{M}]_{0}=0.20 \mathrm{M} \quad(1.0 \mathrm{mmol} / 5 \mathrm{ml}), \quad[\mathrm{M}]$ $($ monomer addition $)=0.10 \mathrm{M}(1.0 \mathrm{mmol} / 10 \mathrm{ml}),\left[\mathrm{I}_{2}\right]_{0}=$ $9.0 \mathrm{mM}$. Solvents as indicated.

Polymerization with $\mathrm{AcClO}_{4}$. The DHF polymerization was also carried out with $\mathrm{AcClO}_{4}$, an oxo acid derivative which is an effective initiator for the cationic oligomerization of styrenes ${ }^{5}$ and hence appears less suitable for living polymerization. The monomer $(0.50 \mathrm{M})$ polymerized smoothly in both toluene and $\mathrm{CH}_{2} \mathrm{Cl}_{2}$ at $-40^{\circ} \mathrm{C}$ to give $100 \%$ conversions in $1 \mathrm{~h}\left(\left[\mathrm{AcClO}_{4}\right]_{0}=0.3-0.6 \mathrm{mM}\right)$.

The MWD of the polymers thus obtained was broader than those with iodine $\left(M_{w} / M_{n}=\right.$ 1.7-2.3) and shifted toward a higher molecular weight region with conversion. In spite of this apparent increase in the polymer molecular weight, however, calculation of the number $(N)$ of polymer chains produced per unit initiator indicated that the formation of longlived polymers by $\mathrm{AcClO}_{4}$ was questionable. The $N$ values, based on the $M_{n}$ by GPC, were in the range of 6-12 for both polymers prepared in toluene and $\mathrm{CH}_{2} \mathrm{Cl}_{2}$, much larger than unity expected for living polymers. Thus the $\mathrm{AcClO}_{4}$-initiated polymerization involves chain transfer and chain-breaking reactions. The polymerization also gave polymers with broad MWDs even at $-78^{\circ} \mathrm{C}$.

In contrast, the $N$ values for the polymers formed by iodine (calculated from Figure 2) were close to those for living polymers: in toluene, $\quad N(\mathrm{obd})=0.3-0.4, \quad N($ calcd $)=0.50$; in $\mathrm{CH}_{2} \mathrm{Cl}_{2}, \quad N(\mathrm{obd}) \sim 1.1, \quad N($ calcd $)=1.0$. These calculated values are based on the report $^{18}$ that the initiation by iodine is bimolecular in toluene and unimolecular in $\mathrm{CH}_{2} \mathrm{Cl}_{2}$ with respect to the initiator.

It should be noted that DHF yielded longlived polymers in the presence of iodine irrespective of solvent polarity, though the living polymerization of linear vinyl and propenyl ethers is feasible only in nonpolar media ${ }^{5}$ (see 

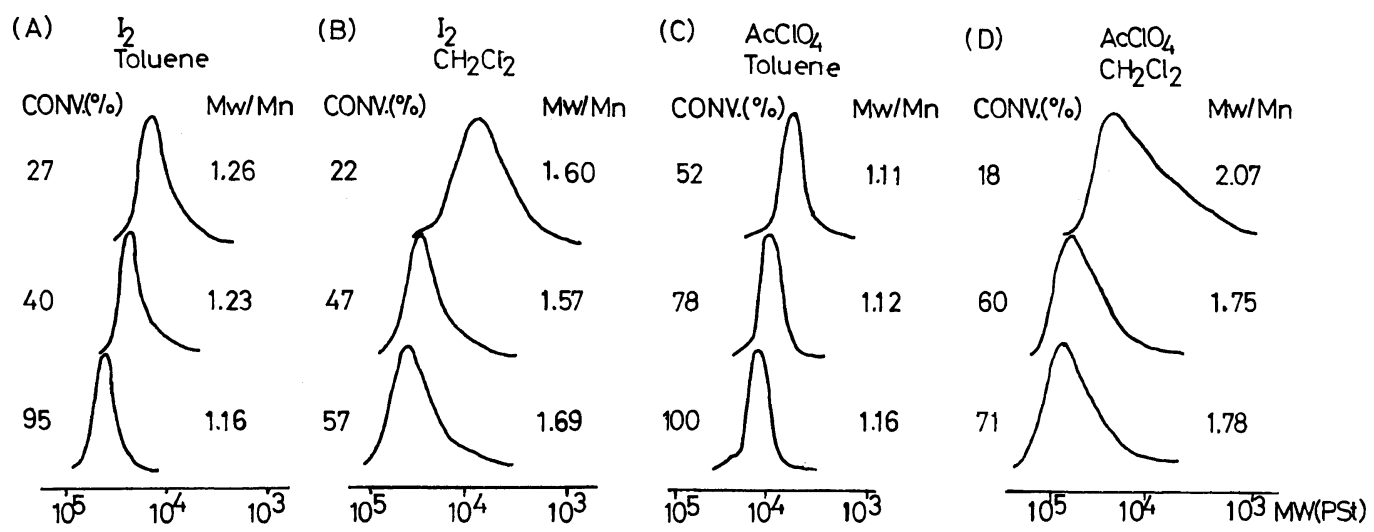

Figure 3. MWD of poly(MeDHF) obtained with iodine or $\mathrm{AcClO}_{4}$ at $-78^{\circ} \mathrm{C}$. $[\mathrm{M}]_{0}$ and $[\mathrm{C}]_{0}:(\mathrm{A}) 0.20 \mathrm{M}$, $1.0 \mathrm{mM}$; (B) $0.50 \mathrm{M}, 1.0 \mathrm{mM}$; (C) $0.20 \mathrm{M}, 1.5 \mathrm{mM}$; (D) $0.50 \mathrm{M}, 0.75 \mathrm{mM}$. Solvents and initiators as indicated.

below). The long-lived poly(DHF)s thus obtained, however, are not perfectly "living," as indicated by their MWDs considerably broader than monodisperse distribution, probably due to chain transfer occurring to some extent.

\section{Polymerization of 5-Methyl-2,3-dihydrofuran}

In order to get an improved living process for a cyclic unsaturated ether, the polymerization of MeDHF was investigated. This $\alpha-$ methyl derivative of DHF seems more suitable for living polymerization than DHF, because it forms a tert.-growing species stabilized by the electron-donating methyl group.

Polymerization with Iodine. Although a large steric hindrance is expected for its trisubstituted internal carbon-carbon double bond, MeDHF exhibited high cationic polymerizability, giving, for example, a $90 \%$ conversion within $30 \mathrm{~min}$ when polymerized with iodine in toluene at $-78^{\circ} \mathrm{C} \quad\left([\mathrm{MeDHF}]_{0}=0.20 \mathrm{M}\right.$, $\left.\left[\mathrm{I}_{2}\right]_{0}=1.0 \mathrm{mM}\right)$. The MeDHF polymerization can thus be carried out at $-78^{\circ} \mathrm{C}$, a temperature lower than that for DHF $\left(-40^{\circ} \mathrm{C}\right)$ and more favorable for living processes.

Figure 3 shows the MWDs of the polymers obtained in $\mathrm{CH}_{2} \mathrm{Cl}_{2}$ and toluene. The MWD curves for both solvents progressively shifted toward a higher molecular weight region with conversion. Importantly, they were consid- erably narrower than that of poly(DHF) formed under similar conditions (see Figure 1); in particular, the MWD of the polymer obtained in toluene was nearly monodisperse $\left(M_{w} / M_{n}=1.1-1.3\right)$.

Figure 4 shows the relationships between the conversion and $M_{n}$ (by GPC) of the polymers. The $M_{n}$ 's for both $\mathrm{CH}_{2} \mathrm{Cl}_{2}$ and toluene were nearly proportional to conversion. The molecular weight of the polymer formed in toluene, also increased with a decrease in the initiator concentration (Figure 5). These results show that long-lived poly(MeDHF) can be prepared with iodine in both polar and nonpolar solvents.

Polymerization with $\mathrm{AcClO}_{4}$. The possibility of living MeDHF polymerization was also investigated with $\mathrm{AcClO}_{4}$ as an initiator, which would promote chain transfer. ${ }^{5}$ Even with this seemingly less promising initiator, poly(MeDHF)s formed at $-78^{\circ} \mathrm{C}$ in $\mathrm{CH}_{2} \mathrm{Cl}_{2}$ and toluene exhibited narrow MWDs (Figure 5) that shifted toward a higher molecular weight region with conversion. In particular, the MWD of the polymer obtained in toluene is almost monodisperse $\left(M_{w} / M_{n} \sim 1.1\right)$. The MWDs of the polymers obtained in $\mathrm{CH}_{2} \mathrm{Cl}_{2}$ were rather broad $\left(M_{w} / M_{n}=1.7-2.1\right)$.

Figures 6 and 7 show the dependences of the $M_{n}$ of polymers on the conversion and initial 


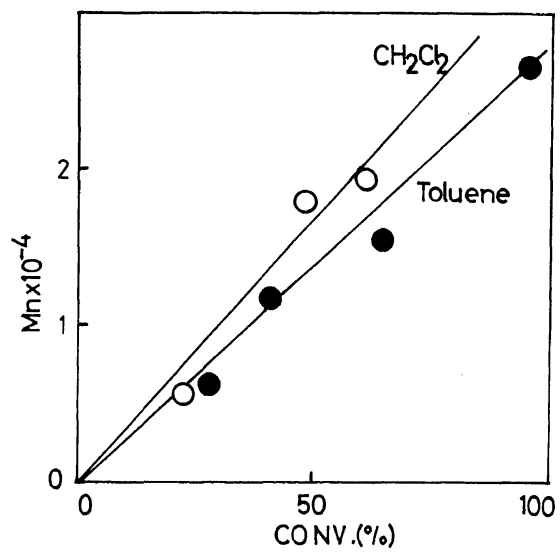

Figure 4. $M_{n}$-conversion plots for poly(MeDHF) obtained with iodine at $-78^{\circ} \mathrm{C}:(\mathrm{O})[\mathrm{M}]_{0}=0.50 \mathrm{M},\left[\mathrm{I}_{2}\right]_{0}=$ $1.0 \mathrm{mM} ;(\bigcirc)[\mathrm{M}]_{0}=0.20 \mathrm{M},\left[\mathrm{I}_{2}\right]_{0}=1.0 \mathrm{mM}$. Solvents as indicated.

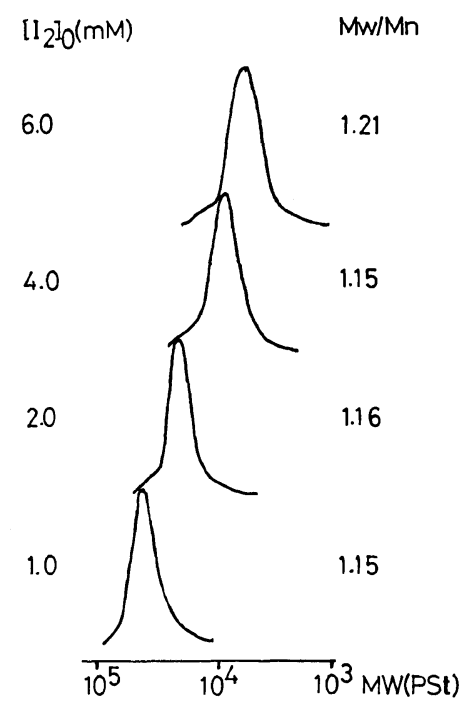

Figure 5. MWD of poly(MeDHF) obtained with iodine at $-78^{\circ} \mathrm{C}$ in toluene at different initiator concentrations $\left[\mathrm{I}_{2}\right]_{0}:[\mathrm{M}]_{0}=0.20 \mathrm{M}$, conversions $=100 \%$.

initiator concentration, respectively. The polymer molecular weight increased nearly proportionally to conversion (Figure 6) and to the reciprocal of the initial $\mathrm{AcClO}_{4}$ concentration (Figure 7) in both toluene and $\mathrm{CH}_{2} \mathrm{Cl}_{2}$. The straight line in Figure 7 indicates the calculated $M_{n}$ values for living polymers when they are formed quantitatively with $\mathrm{AcClO}_{4}$. The

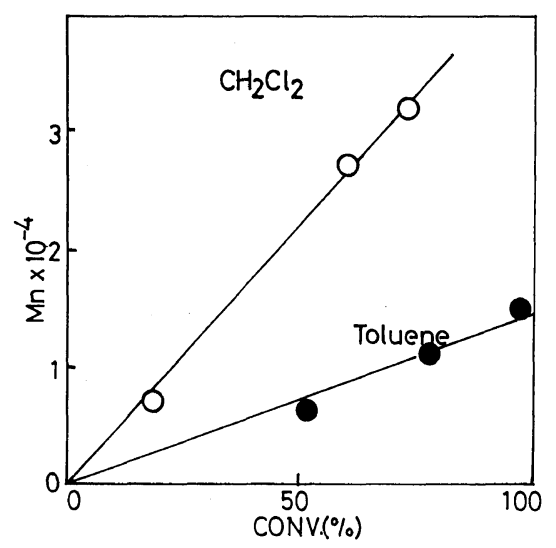

Figure 6. $M_{n}$-conversion plots for poly(MeDHF) obtained with $\mathrm{AcClO}_{4}$ at $-78^{\circ} \mathrm{C}$ : (O) $[\mathrm{M}]_{0}=0.50 \mathrm{M}$, $\left[\mathrm{AcClO}_{4}\right]_{0}=0.75 \mathrm{mM} ;(\bigcirc)[\mathrm{M}]_{0}=0.20 \mathrm{M},\left[\mathrm{AcClO}_{4}\right]=$ $1.5 \mathrm{mM}$. Solvents as indicated.

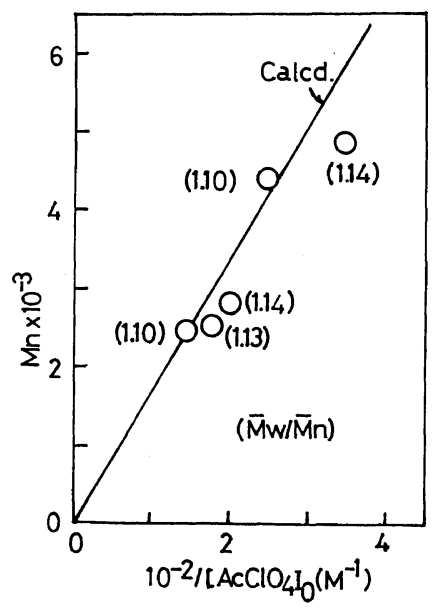

Figure 7. $M_{n}$ of poly(MeDHF) obtained with $\mathrm{AcClO}_{4}$ at $-78^{\circ} \mathrm{C}$ in toluene as a function of the initial initiator concentration $\left[\mathrm{AcClO}_{4}\right]_{0}:[\mathrm{M}]_{0}=0.20 \mathrm{M}$; conversions = $100 \% ; M_{n}$ by VPO. The solid line indicates the calculated $M_{n}$ values for living polymers: $M_{n}=(\mathrm{Wt}$. of $\mathrm{MeDHF}$ polymerized $) /\left[\mathrm{AcClO}_{4}\right]_{0}$. The figures in parentheses are the $M_{w} / M_{n}$ ratios.

agreement between the experimental and calculated values is satisfactory as far as $\left[\mathrm{AcClO}_{4}\right]_{0}$ is not too low.

The results shown in Figures 5-7 show that the polymerization of $\mathrm{MeDHF}$ by $\mathrm{AcClO}_{4}$ in toluene is almost ideal living polymerization, in which monodisperse polymers with con- 

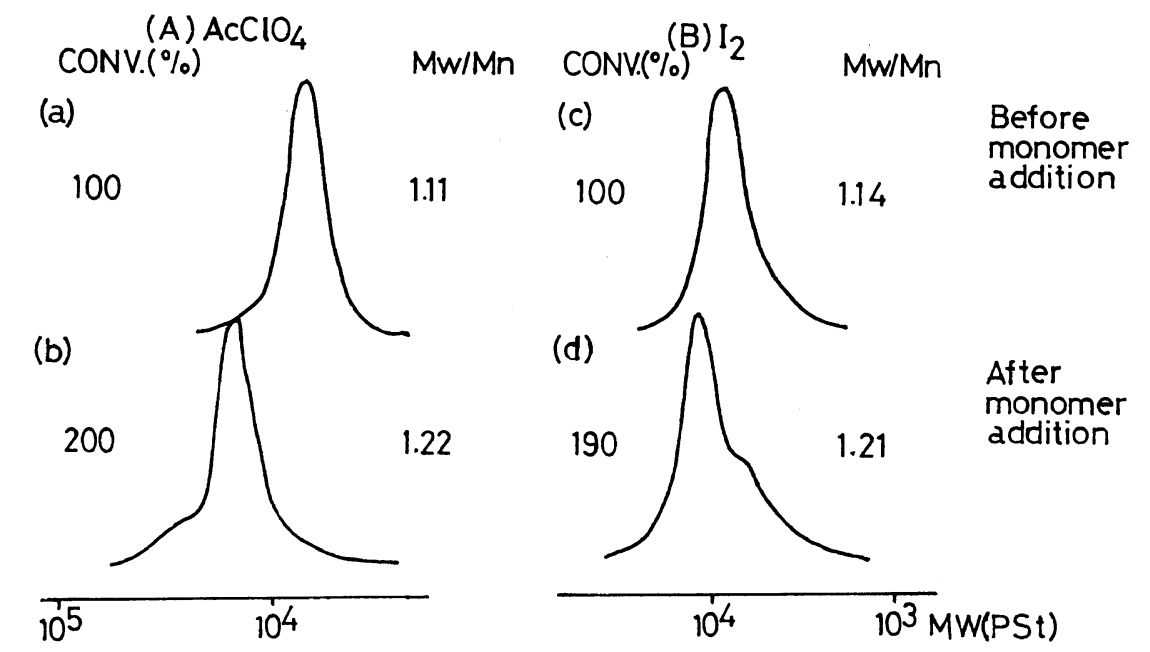

Figure 8. $\mathrm{MWD}$ of poly(MeDHF) obtained with $\mathrm{AcClO}_{4}$ or iodine in toluene at $-78^{\circ} \mathrm{C}$ before (top) and after (bottom) monomer addition: $[\mathrm{M}]_{0}=0.20 \mathrm{M}(1.0 \mathrm{mmol} / 5 \mathrm{ml}) ;[\mathrm{M}]$ (monomer addition) $=0.10 \mathrm{M}$ $(1.0 \mathrm{mmol} / 10 \mathrm{ml})$. (A) $\left[\mathrm{AcClO}_{4}\right]_{0}=4.0 \mathrm{mM}$; (B) $\left[\mathrm{I}_{2}\right]_{0}=6.0 \mathrm{mM}$.

trolled molecular weights can be obtained.

Further evidence for the living nature of the $\mathrm{AcClO}_{4}$-initiated polymerization was obtained in so-called monomer-addition experiments where a new MeDHF feed was added to a completely polymerized solution. Similar experiments with iodine were also performed for comparison. Figure 8 compares the MWDs of the polymers produced before and after such a monomer addition in toluene. With both initiators, the polymer molecular weight clearly increased after the monomer addition, indicating poly(MeDHF) can resume propagation when an additional monomer-feed is supplied. With $\mathrm{AcClO}_{4}$ nearly monodisperse MWD was maintained in the second-stage polymerization, whereas a tailing appeared in the lower molecular weight side in the MWD of the polymer obtained with iodine, probably owing to the formation of new propagating chains by the remaining initiator and/or by chain transfer on the monomer addition.

Thus, the polymerization by $\mathrm{AcClO}_{4}$ is a living process characterized by the absence of chain transfer and termination and complete initiation; iodine generates long-lived polymers but the initiation is slow or incomplete.
The polymerization of $\mathrm{MeDHF}$ by $\mathrm{AcClO}_{4}$ is, to our knowledge, the first example of a living process obtained with an initiator other than iodine (or its mixture with hydrogen iodide).

Other Initiators. The polymerization of $\mathrm{MeDHF}$ by other initiators such as a protonic acid $\left(\mathrm{CH}_{3} \mathrm{SO}_{3} \mathrm{H}\right)$ or metal halides $\left(\mathrm{SnCl}_{4}\right.$ and $\left.\mathrm{BF}_{3} \mathrm{OEt}_{2}\right)$ in toluene at $-78^{\circ} \mathrm{C}$ resulted in polymers with broad MWDs and $M_{n}$ 's almost unchanged with conversion. An equimolar mixture of hydrogen iodide and iodine as an initiating system failed to give polymers but gave only ill-defined oligomers. No attempts were made to analyze this reaction.

\section{Structure of the Polymers}

${ }^{1} \mathrm{H}$ and ${ }^{13} \mathrm{C}$ NMR structural analyses on poly(DHF) and poly(MeDHF) obtained in this study confirmed the expected polymerization pathway via simple opening of the carbon-carbon double bond of the monomers. No evidence was found for the opening of the cyclic ether units by propagation or chain transfer ${ }^{19,20}$ via an oxonium-ion intermediate.

The main-chain carbons of these polymers exhibited a split ${ }^{13} \mathrm{C}$ NMR signal, indicative of the presence of their steric isomers. ${ }^{15,21}$ 
Table I. Effects of monomer structure and reaction conditions on living polymerization of $\alpha, \beta$-disubstituted monomers ${ }^{\mathrm{a}}$

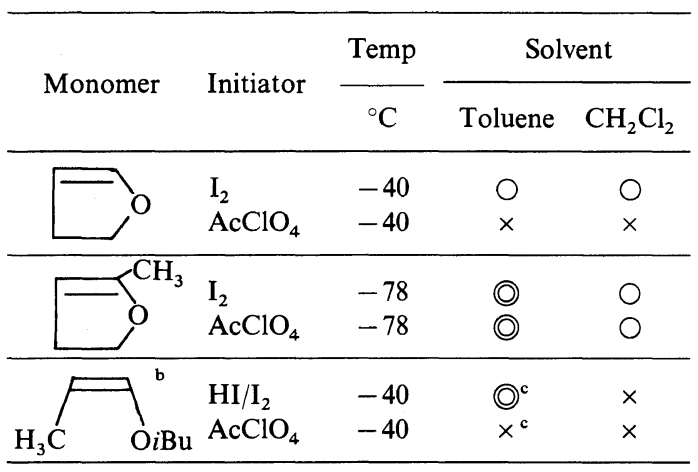

a (), Living/long-lived polymers with nearly monodisperse MWDs; $\bigcirc$, Long-lived polymers with broader MWDs; $\times$, Non-living polymers.

b From ref 4

c Solvent: $n$-hexane.

\section{Effects on Monomer Structure on Living} Polymerization

Table I compares the reaction conditions for the living polymerization of the cyclic unsaturated ethers, DHF and MeDHF, with those for the corresponding linear monomer, isobutyl propenyl ether (IBPE). ${ }^{4}$ It shows the effects of monomer structure (cyclic $v s$. linear) and the $\alpha$-methyl substituent (DHF vs. MeDHF).

First, the cyclic ethers DHF and MeDHF yielded living/long-lived polymers in both polar and nonpolar media with iodine as an initiator. Moreover, living/long-lived poly(MeDHF) was also obtained with $\mathrm{AcClO}_{4}$ in these solvents. In contrast, the living polymerization of the linear counterpart, IBPE, is feasible only with iodine (or its mixture with hydrogen iodide) and only in nonpolar solvents. ${ }^{4}$ This difference suggests that $\beta$-proton elimination (chain transfer) is less favorable in the rigid cyclic propagating ends derived from DHF and MeDHF, probably because the $\beta$ proton can hardly take the required transperiplanar position against the $p$-orbital of the active site.

Second, with $\mathrm{AcClO}_{4}$ as an initiator in toluene, MeDHF gives almost perfect living polymers having nearly monodisperse MWDs and predictable molecular weights, whereas DHF results in non-living polymers with broader MWDs. When polymerized by iodine, both monomers do form long-lived polymers, but the MWD is narrower for poly(MeDHF) than poly(DHF). These facts indicate that MeDHF, as an $\alpha$-methyl derivative of $\mathrm{DHF}$, is superior to the parent for living polymerization. Evidently, because of the presence of an electron-donating $\alpha$-methyl group, the growing species derived from MeDHF is tertiary and hence highly stabilized against chain transfer, so that it can retain a long lifetime even when associated with the perchlorate counteranion that is known to promote the $\beta$-proton elimination. ${ }^{5}$

\section{REFERENCES}

1. T. Ohtori, Y. Hirokawa, and T. Higashimura, Polym. J., 11, 471 (1979).

2. M. Miyamoto, M. Sawamoto, and T. Higashimura, Macromolecules, 17, 265 (1984).

3. M. Miyamoto, M. Sawamoto, and T. Higashimura, Macromolecules, 17, Oct. issue (1984).

4. T. Higashimura, A. Tanizaki, and M. Sawamoto, $J$. Polym. Sci., Polym. Chem. Ed., in press.

5. As a recent review, see $\mathrm{T}$. Higashimura and $\mathbf{M}$. Sawamoto, Adv. Polym. Sci., 62, 49 (1984).

6. T. Higashimura and O. Kishiro, Polym. J., 9, 87 (1977).

7. T. Higashimura, M. Mitsuhashi, and M. Sawamoto, Macromolecules, 12, 178 (1979).

8. T. Higashimura, H. Teranishi, and M. Sawamoto, Polym. J., 12, 393 (1980).

9. T. Higashimura, Y.-X. Deng, and M. Sawamoto, Polym. J., 15, 385 (1983).

10. D. A. Barr and J. B. Rose, J. Chem. Soc., 3766 (1954).

11. B. Kamo, S. Kurashige, and S. Furusawa, Kogyo Kagaku Zasshi, 73, 580 (1970).

12. J. A. Moore and R. Wille, Polym. Prepr., Div. Polym. Chem., Am. Chem. Soc., 24 (2), 317 (1983).

13. G. J. Schmitt and C. Schuerch, J. Polym. Sci., 49, 287 (1961).

14. A. Nishioka and Y. Hachihama, Kogyo Kagaku Zasshi, 65, 1120 (1962).

15. B. Kamo, N. Suzuki, K. Ogawa, and S. Furusawa, Nippon Kagakukaishi, 610 (1973).

16. M. F. Ansell and D. A. Thomas, J. Chem. Soc., 1163 
(1958).

17. T. Masuda and T. Higashimura, J. Macromol. Sci., Chem., A5, 547 (1971).

18. S. Okamura, N. Kanoh, and T. Higashimura, Makromol. Chem., 47, 35 (1961).

19. S. Aoshima and T. Higashimura, J. Polym. Sci.,
Polym. Chem. Ed., in press.

20. T. Higashimura, K. Sanenobu, and S. Aoshima, to be published.

21. J. A. Moore, R. Wille, and K. J. Miller, Polym. Prepr., Div. Polym. Chem., Am. Chem. Soc., 24 (2), 333 (1983). 